\title{
Luminescence of Ion-Pair States of Halogens in Liquid Perfluorocarbons.
}

\author{
Vadim A. Alekseev, ${ }^{* \dagger}$ Peter J. M. van der Burgt, ${ }^{\ddagger}$ and John G. McCaffrey ${ }^{\S}$ \\ ${ }^{\dagger}$ Institute of Physics, St. Petersburg State University, Ul’janovskaja St.1, Peterhof, 198504 St. Petersburg, Russia \\ ${ }^{\ddagger}$ Department of Experimental Physics, National University of Ireland Maynooth, Ireland \\ ${ }^{\S}$ Department of Chemistry, National University of Ireland Maynooth, Ireland
}

ABSTRACT: The $\mathrm{I}_{2}\left(\mathrm{D}^{\prime}-\mathrm{A}^{\prime}\right)$ luminescence in liquid $\mathrm{C}_{7} \mathrm{~F}_{16}, \mathrm{C}_{8} \mathrm{~F}_{18}, \mathrm{C}_{9} \mathrm{~F}_{20}$, and $\mathrm{C}_{12} \mathrm{~F}_{26}$ has been observed following irradiation with visible (within the $\mathrm{I}_{2} \mathrm{X} \rightarrow$ $\mathrm{B}$ band region) and UV $(\lambda<300 \mathrm{~nm})$ lasers. The band is shifted by $\sim 2000$ $\mathrm{cm}^{-1}$ to the red relative to the gas phase and is significantly broader (fwhm $\approx$ $3000 \mathrm{~cm}^{-1}$ vs $500 \mathrm{~cm}^{-1}$ in the gas phase). Two-color excitation of other halogens in $\mathrm{C}_{n} \mathrm{~F}_{2 n+2}$ solvents revealed similarly shifted and strongly broadened $\mathrm{D}^{\prime}-\mathrm{A}^{\prime}$ bands of $\mathrm{Br}_{2}, \mathrm{IBr}$, and $\mathrm{BrCl}$. The stability of the ion-pair states of halogens in room temperature liquids opens new experimental opportunities for condensed phase studies and may be of applied interest considering the increasing industrial applications of perfluorocarbons.

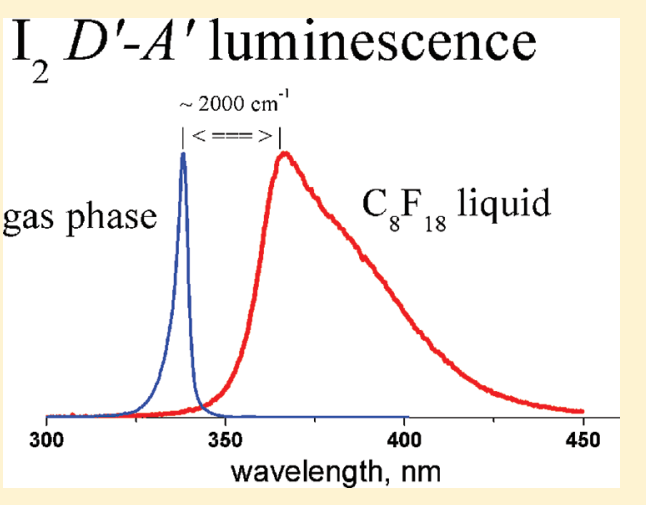

\section{INTRODUCTION}

The $\mathrm{I}_{2}$ molecule has strongly bound ion-pair states correlating to $\mathrm{I}^{+}\left({ }^{3} \mathrm{P}_{J=0,1,2},{ }^{1} \mathrm{D}_{2},{ }^{1} \mathrm{~S}_{0}\right)+\mathrm{I}^{-}\left({ }^{1} \mathrm{~S}_{0}\right)$ dissociation asymptotes. These states may be accessed optically by one photon absorption from the ground state or via the intermediate valence state $I_{2}(B)$ using optical-optical double resonance,

$$
\mathrm{I}_{2}\left(\mathrm{X}_{0_{\mathrm{g}}^{+}}^{+}\right)+h \nu_{1} \rightarrow \mathrm{I}_{2}\left(\mathrm{~B}_{0_{\mathrm{u}}^{+}}^{+}\right)+h \nu_{2} \rightarrow \mathrm{I}_{2}\left(\mathrm{E}_{0_{\mathrm{g}}^{+}}\right)
$$

When an ion-pair state is excited in a mixture with gaseous or condensed rare gases, interactions with the environment transfer population to the lowest ion-pair state $D^{\prime} 2_{g}$, which decays radiatively to the valence $A^{\prime} 2_{u}$ state. In pump-probe studies of energy relaxation processes, ${ }^{1}$ the $\mathrm{I}_{2}\left(\mathrm{D}^{\prime} \rightarrow \mathrm{A}^{\prime}\right)$ transition provides a monitor of transient population in the $\mathrm{B}$ state. On the other hand, solvation of $\mathrm{I}_{2} \mathrm{D}^{\prime}$ in condensed $\mathrm{Rg}$ gases is of interest in its own right and has been the subject of several experimental ${ }^{2-7}$ and theoretical ${ }^{8,9}$ investigations.

Perfluorocarbons (PFC), $\mathrm{C}_{n} \mathrm{~F}_{2 n+2}$, are known as inert solvents, which weakly interact with the excited states of the solute molecules. Early studies revealed exceptionally small solvation shifts in PFC in comparison with other molecular solvents, including in particular linear hydrocarbons $\mathrm{C}_{n} \mathrm{H}_{2 n+2}{ }^{10}$

$\mathrm{I}_{2}$ is weakly soluble in the perfluorocarbons, and upon addition of $\mathrm{I}_{2}$ crystals the originally colorless liquids acquire a faint violet color. It is known from early studies that the solution color depends on the strength of interaction between $\mathrm{I}_{2}$ and solvent molecules. ${ }^{11}$ The interaction with $\mathrm{C}_{n} \mathrm{~F}_{2 n+2}$ is very weak as evidenced by the fact that the envelope of $\mathrm{I}_{2}(\mathrm{X} \rightarrow \mathrm{B})$ absorption band in these solvents is nearly the same as in the gas phase. ${ }^{12,13}$
In this contribution we report on studies of halogen in $\mathrm{C}_{n} \mathrm{~F}_{2 n+2}, n=7-9,12$, liquids using the optical-optical double resonance technique. Observation of $\mathrm{I}_{2}\left(\mathrm{D}^{\prime} \rightarrow \mathrm{A}^{\prime}\right)$ luminescence in PFC solvents has been briefly reported in ref 14 . This contribution discusses studies of iodine in PFC solvents in detail and reports on the observation of the $D^{\prime} \rightarrow A^{\prime}$ luminescence bands of $\mathrm{Br}_{2}, \mathrm{IBr}$, and $\mathrm{BrCl}$ in $\mathrm{PFC}$ solvents. Stability of the ion-pair states of halogens in room temperature liquids opens new experimental opportunities for condensed phase studies and is of applied interest considering the increasing industrial applications of perfluorocarbons.

\section{EXPERIMENTAL SECTION}

The $\mathrm{I}_{2}\left(\mathrm{D}^{\prime}\right)$ luminescence was observed following simultaneous irradiation with visible (within the $\mathrm{X} \rightarrow \mathrm{B}$ band region) and $\mathrm{UV}$ $(\lambda<300 \mathrm{~nm})$ lasers. The visible laser was either the second harmonic of a Nd:YAG laser (Quantel, YG 980E-10), $532 \mathrm{~nm}$, or the fundamental output of a dye laser (Quantel TDL-90), and the UV beam was the frequency doubled output of the dye laser. Samples were contained in a $1 \mathrm{~cm}$ quartz cell positioned in front of the entrance slit of a $0.5 \mathrm{~m}$ Acton Research SP500i monochromator. Time-resolved luminescence spectra were recorded using an Andor Technologies iStar DH720 iCCD (intensified charge coupled device) detector. Details of the optical arrangement and detection system have previously been presented. $^{15}$

The measurements on the solutions of other halogens in PFC liquids were performed using a Lambda Physik laser

Received: November 15, 2011

Revised: January 9, 2012

Published: January 10, 2012 
system consisting of a LEXTRA50 excimer laser pumping an LPD3002 tunable dye laser. In these experiments, the visible fundamental of the dye laser (typically in the $500 \mathrm{~nm}$ region) was used in combination with the UV beam obtained by frequency doubling. In some of the experiments, a small fraction of the $\mathrm{XeCl}$ pump laser beam $(\lambda=308 \mathrm{~nm})$ was used instead of the second harmonic. Spectra were recorded using an Acton $0.30 \mathrm{~m}$ SP-300i scanning monochromator equipped with a 955 Hamamatsu photomultiplier.

\section{RESULTS AND DISCUSSION}

Figure 1 shows the electronic states of the $I_{2}$ molecule discussed in the present work. Luminescence spectra of $I_{2}$ in

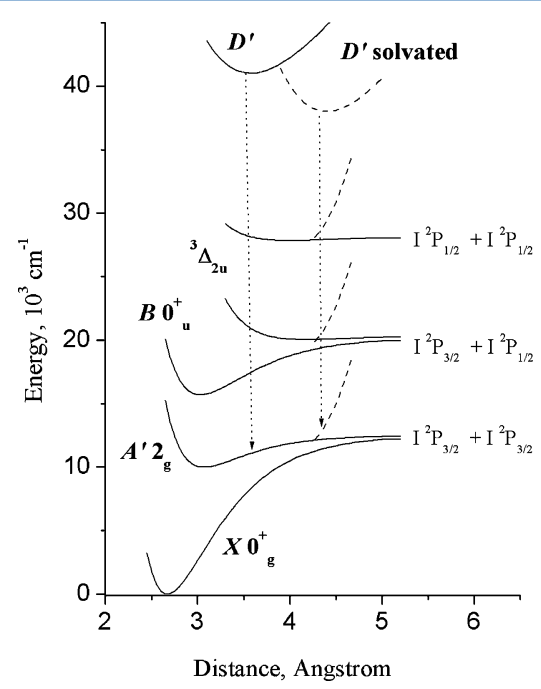

Figure 1. Potential curves of some electronic states of the $\mathrm{I}_{2}$ molecule. The dashed curves schematically show potential curves in solution. In contrast to the ion-pair states, the valence states in condensed environment have no dipole moment, and for the equilibrium $\mathrm{I}_{2}\left(\mathrm{D}^{\prime}\right)-$ $\mathrm{C}_{n} \mathrm{~F}_{2 n+2}$ distance, the $\mathrm{I}_{2}\left(\mathrm{~A}^{\prime}\right)-\mathrm{C}_{n} \mathrm{~F}_{2 n+2}$ interaction is repulsive. The vertical dotted lines schematically show $\mathrm{D}^{\prime} \rightarrow \mathrm{A}^{\prime}$ transitions in the gas phase and in solutions.

liquid PFC following two-color laser excitation are shown in Figure 2a. The spectra display two bands at 370 and $560 \mathrm{~nm}$ attributed to the $\mathrm{D}^{\prime} \rightarrow \mathrm{A}^{\prime}$ and $\mathrm{D}^{\prime} \rightarrow{ }^{3} \Delta_{2 \mathrm{u}}$ transitions respectively. For comparison, Figure $1 \mathrm{~b}$ shows a spectrum of $\mathrm{I}_{2}$ in a gaseous mixture with $\mathrm{CF}_{4}$ recorded in this study. Molecules in ion-pair states possess large instantaneous dipoles $D \approx e R_{\mathrm{e}}$, where $e$ is the electron charge and $R_{\mathrm{e}}$ is equilibrium internuclear separation. According to ref 9 , interaction with the polarizable environment breaks the inversion symmetry of the ion-pair states causing charge localization and the establishment of a permanent molecular dipole moment. The dipole-induced dipole interaction with the solvent lowers the ion-pair state energy with the result that the $\mathrm{D}^{\prime} \rightarrow \mathrm{A}^{\prime}$ and $\mathrm{D}^{\prime} \rightarrow{ }^{3} \Delta_{2 \mathrm{u}}$ bands are shifted by $\sim 2000 \mathrm{~cm}^{-1}$ from their positions in the gas phase. The $\mathrm{A}^{\prime}$ state on the other hand does not possess a dipole moment, and in contrast to the gas phase, the $\mathrm{D}^{\prime} \rightarrow \mathrm{A}^{\prime}$ band in PFC liquids is red degraded implying that in the FranckCondon region the $\mathrm{I}_{2}\left(\mathrm{~A}^{\prime}\right)-\mathrm{C}_{n} \mathrm{~F}_{2 n+2}$ interaction potential is repulsive (Figure.1).

Figure 3 summarizes time-resolved measurements of the $\mathrm{D}^{\prime}$ $\rightarrow \mathrm{A}^{\prime}$ luminescence. The time dependence of the $\mathrm{D}^{\prime} \rightarrow \mathrm{A}^{\prime}$ emission in a gas phase mixture with $\mathrm{Ar}$ is shown for comparison. The $\mathrm{D}^{\prime}$ state lifetime obtained from these data is

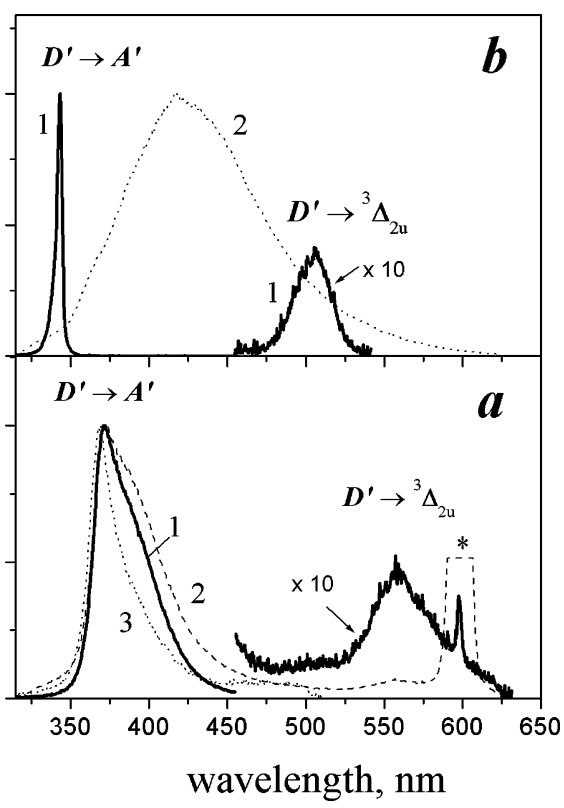

Figure 2. (a) Luminescence spectrum following two photon excitation $\left(\lambda_{1}=595 \mathrm{~nm}\right.$ and $\left.\lambda_{2}=297.5 \mathrm{~nm}\right)$ of $\mathrm{I}_{2}$ dissolved in (1) $\mathrm{C}_{8} \mathrm{~F}_{18}$ at $T=$ $300 \mathrm{~K}$ (spectrum in $\mathrm{C}_{9} \mathrm{~F}_{20}$ solvent is identical in the scale of plot), (2) $\mathrm{C}_{7} \mathrm{~F}_{16}$ at $T=300 \mathrm{~K}$, and $(3) \mathrm{C}_{12} \mathrm{~F}_{26}$ at $T=360 \mathrm{~K}$ (spectra in $\mathrm{C}_{8} \mathrm{~F}_{18}$ and $\mathrm{C}_{9} \mathrm{~F}_{20}$ solvents at this temperature have nearly identical shape). The feature marked with $*$ is the scattered laser light. (b) Luminescence spectra of (1) gas phase mixture of $\mathrm{I}_{2}$ with $\mathrm{CF}_{4}, P=1 \mathrm{bar}$, and (2) pure $\mathrm{C}_{7} \mathrm{~F}_{16}$ liquid, one photon excitation $\lambda_{\mathrm{ex}}=286.615 \mathrm{~nm}$.



Figure 3. Intensity of $\mathrm{D}^{\prime} \rightarrow \mathrm{A}^{\prime}$ luminescence as a function of time following two photon excitation $\left(\lambda_{1}=595 \mathrm{~nm}+\lambda_{2}=297.5 \mathrm{~nm}\right)$ of $\mathrm{I}_{2}+$ $\mathrm{C}_{n} \mathrm{~F}_{2 n+2}$ solutions, $\mathrm{I}_{2}+$ Ar gas phase mixture $\left(P_{\mathrm{I}_{2}} \approx 0.3 \mathrm{mbar}, P_{\mathrm{Ar}}=1.5\right.$ bar) at $T=300 \mathrm{~K}$. Results for $\mathrm{C}_{8} \mathrm{~F}_{18}$ and $\mathrm{C}_{9} \mathrm{~F}_{20}$ (not shown) solvents are nearly identical. Temporal behavior of luminescence following one photon excitation $(\lambda=297.5 \mathrm{~nm})$ of pure $\mathrm{C}_{7} \mathrm{~F}_{16}$ is shown for comparison.

$7.9 \pm 0.5 \mathrm{~ns}$, which is in good agreement with results of previous measurements. ${ }^{16}$ In $\mathrm{C}_{8} \mathrm{~F}_{18}$ and $\mathrm{C}_{9} \mathrm{~F}_{20}$ solvents, the $\mathrm{D}^{\prime}$ state lifetime is $3.5 \pm 0.5 \mathrm{~ns}$. In the $\mathrm{C}_{7} \mathrm{~F}_{16}$ solvent, the $\mathrm{D}^{\prime} \rightarrow \mathrm{A}^{\prime}$ luminescence is seen only during the UV laser pulse. The weak, long-lived component of the signal in $\mathrm{C}_{7} \mathrm{~F}_{16}$ is solvent luminescence, which is spectrally overlapped with the $\mathrm{D}^{\prime} \rightarrow$ $\mathrm{A}^{\prime}$ band (Figure.1b). The solvent luminescence lifetime is $48 \pm$ $1 \mathrm{~ns}$ vs $13 \pm 0.5 \mathrm{~ns}$ in the saturated $\mathrm{I}_{2}$ solution implying that $\mathrm{I}_{2}$ quenches the excited state of $\mathrm{C}_{7} \mathrm{~F}_{16}$. Energy transfer from $\mathrm{I}_{2}\left(\mathrm{D}^{\prime}\right)$ to $\mathrm{C}_{7} \mathrm{~F}_{16}$ most likely takes place as well and explains the short $\mathrm{I}_{2}\left(\mathrm{D}^{\prime}\right)$ lifetime in this solvent. 
Along with experiments at room temperature, solutions were also studied at elevated temperatures, including solution in $\mathrm{C}_{12} \mathrm{~F}_{26}$, which melts at $T=350 \mathrm{~K}$. Experiments showed that the $\mathrm{D}^{\prime} \rightarrow \mathrm{A}^{\prime}$ band has a nearly identical shape as in $\mathrm{C}_{8} \mathrm{~F}_{18}$ and $\mathrm{C}_{9} \mathrm{~F}_{20}$ solvents at the same temperature (Figure.2a). The $\mathrm{D}^{\prime}$ state lifetime is also approximately the same. When a solution of iodine in $\mathrm{C}_{12} \mathrm{~F}_{26}$ is cooled, its color changes from violet in the liquid to brown in the solid state. A similar effect was observed upon cooling solutions of $\mathrm{I}_{2}$ in $\mathrm{C}_{8} \mathrm{~F}_{18}$ and $\mathrm{C}_{9} \mathrm{~F}_{20}$ below the freezing point. Two-color excitation of $\mathrm{I}_{2}$ in $\mathrm{C}_{n} \mathrm{~F}_{2 n+2}$ solids $(n=$ $7-9,12)$, prepared by cooling liquid solutions, yields no $\mathrm{D}^{\prime}$ luminescence. The effect of temperature on color of iodine solutions has been known for a long time. ${ }^{11} \mathrm{~A}$ further study of this effect for iodine solutions in perfluorocarbons appears of interest.

Following successful observation of the $\mathrm{I}_{2}\left(\mathrm{D}^{\prime}\right)$ luminescence, we studied solutions of other halogens in PFC liquids. A spectrum of $\mathrm{Br}_{2}$ in the $\mathrm{C}_{8} \mathrm{~F}_{18}$ solvent is shown in Figure 4a. Like

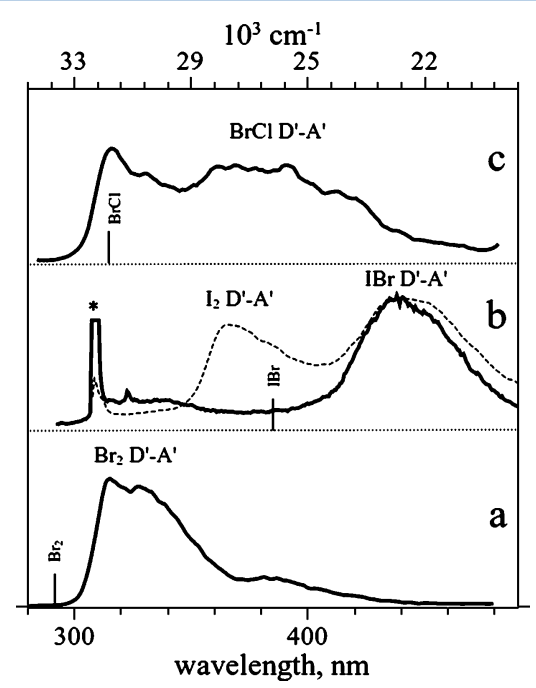

Figure 4. Luminescence spectra of halogen solutions in perfluorocarbons at $T=300 \mathrm{~K}$ following two-color laser excitation: (a) $\mathrm{Br}_{2}$ in $\mathrm{C}_{8} \mathrm{~F}_{18}$, excitation $\lambda_{1}=500 \mathrm{~nm}$ and $\lambda_{2}=250 \mathrm{~nm}$; (b) $\mathrm{Br}_{2}+\mathrm{Cl}_{2}$ in $\mathrm{C}_{9} \mathrm{~F}_{20}$, excitation $\lambda_{1}=510 \mathrm{~nm}$ and $\lambda_{2}=255 \mathrm{~nm}$; (c) $\mathrm{Br}_{2}+\mathrm{I}_{2}$ in $\mathrm{C}_{8} \mathrm{~F}_{18}$, solid line $=$ excess of $\mathrm{Br}_{2}$, dotted line $=$ excess of $\mathrm{I}_{2}$, excitation $\lambda_{1}=500 \mathrm{~nm}$ and $\lambda_{2}=308 \mathrm{~nm} ; *=$ scattered laser light. Similar to $\mathrm{I}_{2}$ (Figure $2 \mathrm{~b}$ ), $\mathrm{D}^{\prime}$ $\rightarrow \mathrm{A}^{\prime}$ transition of $\mathrm{Br}_{2}, \mathrm{BrCl}$, and $\mathrm{IBr}$ in the gas phase is a relatively narrow (fwhm $\approx 500 \mathrm{~cm}^{-1}$ ), blue degraded band. Vertical sticks indicate the $\mathrm{D}^{\prime} \rightarrow \mathrm{A}^{\prime}$ position in the gas phase.

the case of $\mathrm{I}_{2}$ (Figure.2), the spectrum displays a shifted and broadened band assigned to the $\mathrm{Br}_{2}\left(\mathrm{D}^{\prime} \rightarrow \mathrm{A}^{\prime}\right)$ transition. The shift relative to the gas phase is $2000 \mathrm{~cm}^{-1}$, that is, approximately the same as for $\mathrm{I}_{2}\left(\mathrm{D}^{\prime} \rightarrow \mathrm{A}^{\prime}\right)$. Figure $3 \mathrm{~b}$ shows spectra recorded after adding $\mathrm{I}_{2}$ to saturated $\mathrm{Br}_{2}$ solution in $\mathrm{C}_{8} \mathrm{~F}_{18}$. Along with the $\mathrm{D}^{\prime} \rightarrow \mathrm{A}^{\prime}$ bands of $\mathrm{I}_{2}$ and $\mathrm{Br}_{2}$, spectra display a new band at $440 \mathrm{~nm}$ assigned to the $\operatorname{IBr}\left(\mathrm{D}^{\prime} \rightarrow \mathrm{A}^{\prime}\right)$ transition. Finally, the spectrum in Figure $3 \mathrm{c}$ was recorded after bubbling $\mathrm{Cl}_{2}$ gas through a saturated $\mathrm{Br}_{2}$ solution. A broad band at $375 \mathrm{~nm}$ is assigned to $\mathrm{BrCl}\left(\mathrm{D}^{\prime} \rightarrow \mathrm{A}^{\prime}\right)$ transition. However no $\mathrm{Cl}_{2}\left(\mathrm{D}^{\prime} \rightarrow \mathrm{A}^{\prime}\right)$ luminescence in the PFC solvents was observed in the present experiments. Search for $\operatorname{ICl}\left(D^{\prime} \rightarrow A^{\prime}\right)$ luminescence was also unsuccessful. It should be noted that the present test experiments were conducted within a short time span and were mainly aimed to confirm the stability of the
$\mathrm{D}^{\prime}$ state of other halogens in PFC solutions. A more systematic study would likely yield a wealth of new, interesting results.

\section{SUMMARY AND OUTLOOK}

The present study has shown that chemically reactive high-lying ion-pair states of halogens are stable with respect to chemical reaction and fast predissociation in liquid perfluorocarbons at room temperature. Along with the exceptional chemical inertness, a peculiar property of PFC liquids is their transparency in the UV and Vac UV regions, which extend down to $160 \mathrm{~nm} .{ }^{17}$ The absorption spectrum of $\mathrm{I}_{2}$ vapor in the Vac UV displays a broad quasi-continuum in the $175-210 \mathrm{~nm}$ region corresponding to the transition to the ion-pair state $\mathrm{D}$ $0^{+}{ }_{u}^{18}$ and test experiments have already demonstrated population of the $\mathrm{D}^{\prime}$ state following one photon excitation in this spectral region. ${ }^{19}$

The stability of the ion-pair states in room temperature liquids enables the application of the pump-probe method supplemented with sensitive luminescence detection techniques to study energy relaxation in the valence states, recombination of halogen atoms following photodissociation via excitation to a repulsive valence state, long-range photoinduced chargetransfer between atoms, and solvation dynamics. An applied aspect of the present study concerns the lasing properties of the $\mathrm{D}^{\prime} \rightarrow \mathrm{A}^{\prime}$ transition. An optically pumped $\mathrm{I}_{2}\left(\mathrm{D}^{\prime} \rightarrow \mathrm{A}^{\prime}\right)$ gaseous laser has been demonstrated many years ago. ${ }^{20}$ The large spectral width of the charge-transfer bands of halogens in PFC solvents and their bound-free character (due to repulsive guest-host interaction in the lower state) make these solutions potentially interesting as novel media for tunable lasers, pulse amplifiers, and broad band luminophors.

\section{AUTHOR INFORMATION}

\section{Corresponding Author}

*Phone: (7)921-9723783. Fax: (7)812-4287240. E-mail address: vadim-alekseev@mail.ru.

\section{ACKNOWLEDGMENTS}

V.A.A. thanks Science Foundation Ireland for financial support via the Walton Visitor Award 07/W.1/I1819.

\section{REFERENCES}

(1) Apkarian, V. A.; Schwentner, N. Chem. Rev. 1999, 99, 1481and references cited therein.

(2) Macler, M.; Heaven, M. C. Chem. Phys. 1991, 151, 219.

(3) Fei, S.; Zheng, X.; Heaven, M. C.; Tellinghuisen, J. J. Chem. Phys. 1992, 97, 6057.

(4) Zadoyan, R.; Li, Z.; Ashijian, P.; Martens, C. C.; Apkarian, V. A. Chem. Phys. Lett. 1994, 218, 504.

(5) Zadoyan, R.; Li, Z.; Martens, C. C.; Apkarian, V. A. J. Chem. Phys. 1994, 101, 6648.

(6) Helbing, J.; Chergui, M. J. Chem. Phys. 2001, 115, 6158.

(7) Helbing, J.; Chergui, M. J. Lumin. 2001, 64-65, 611.

(8) Batista, V. S.; Coker, D. F. J. Chem. Phys. 1997, 106, 6923.

(9) Yu, N.; Coker, D. F. Mol. Phys. 2004, 102, 1031.

(10) Maciejewski, A. J. Photochem. Photobiol. A 1990, 51, 87.

(11) Andrews, L. J.; Keefer, R. M. Molecular Complexes of Halogens. In Advances in Inorganic Chemistry and Radiochemistry; Emeleus, H. J., Sharpe, A. G., Eds.; Academic Press: New York, 1975 and references therein.

(12) Evans, D. F. J. Chem. Phys. 1955, 23, 1424.

(13) Voight, E. M. J. Phys. Chem. 1968, 72, 3300.

(14) Alekseev, V. A., McCaffrey J. G. Presented at the 30th International Symposium on Free Radicals, Savonlinna, 2009 
(15) Collier, M. A.; McCaffrey, J. G. J. Chem. Phys. 2003, 119, 11878.

(16) Jewsbury, P. J.; Lawley, K. P.; Ridley, T.; Al-Adel, F. F.; Langridge-Smith, P. R. R.; Donovan, R. J. Chem. Phys. 1991, 151, 109.

(17) Andres, Y. Nucl. Instrum. Methods A 2002, 486, 590.

(18) Hiraya, A.; Shobatake, K.; Donovan, R. J.; Hopkirk, A. J. Chem. Phys. 1988, 88, 52.

(19) Alekseev, V. A.; McCaffrey, J. G.; Schwentner, N.; Timonen, R. New experimental and Theoretical developments in molecular spectroscopy: Atmospheric and Astrophysical applications. Synchrotron SOLEIL, Saint Aubin,2010.

(20) Mikheev, L. D.; Shirokikh, A. P.; Startzev, A. V.; Zuev, V. S. Opt. Commun. 1978, 26, 237. 